\title{
Study of Quality Process Control in Distance Education with Dual-Mode Teaching
}

\author{
Chunye Tuo
}

\begin{abstract}
In this paper, the quality process control measures in distance education with dual-mode teaching were studied. The design of this kind distance education system could be developed by using the unity $3 D$ and VR/AR device, and it contains both teaching mode of both synchronous and asynchronous. The process control measures could be taken from the teachers, learners and the developers of the platform to guarantee the teaching quality. If the teacher got better professional development and the learner got better study ability and strategies and the platform have good interactions interpersonal and human machine, and the instructional design were proper, the teaching effect will be good enough and more learner could hope to adopt this teaching method.
\end{abstract}

Index Terms-Distance education, quality process control, teaching mode, unity, VR/AR.

\section{INTRODUCTION}

In recent years, rapid developments in Internet technology have important influence on education. One of the most important changes in education is the distance education, which is also known as distance learning or e-learning. Distance learning is used to define education where educators and learners are physically separated and the purposes of distance learning are to overcome barriers of place and time and allow the education to reach the persons unable to attend courses.

The disadvantages are the lack of eye contact between the learners and the lecturers and the student must be more active in education environment. The main advantage of distance learning is its flexibility that the students can study wherever, whenever, and whatever he/she wants.

Current distance learning systems still present restrictions, such as support to interconnection of learning systems available in scalable, open, dynamic, and heterogeneous environments [1].

The most popular, widely used and well-known learning management systems (LMSs) abroad are ATutor, Blackboard, Claroline, Desire2Leam (D2L), Docebo, Dokeos, eFront, Moodle, OLAT, and Sakai [2]. And there are many learning management systems (LMSs) in China, most of which are the Internet-based distance education with mobile app.

Quality assurance is the fundamental pillar of higher education development and continues to remain an integral

Manuscript received February 20, 2019; revised June 27, 2019. This work was supported in part by Shaanxi Xueqian Normal University under Grant 2018YBRS34 and Xi'an Social Science Planning Fund(Grant nos. 19Y103 and 19Y107)

Chuye Tuo is with the Shaanxi Xueqian Normal University, Xi'an, China (e-mail: 329973949@qq.com). part of the distance education process. There are many scholars have been studied the quality assurance measures. The study of Oyaid and Al-Hosan shows that the availability of quality in virtual distance learning is a very important issue for any academic course, program, and educational environment [3]. Pitsoe and Dichaba emphasize that the quality assurance of the distance education is cultural hegemony, and the learner is ruled both outer force and inner ideas [4].

In China, although the quality assurance of distance education has made continuous progress, the overall situation has not changed, the national macro-quality monitoring system is still imperfect, the internal quality assurance system of institutions is not perfect, and the quality standards are inconsistent. X.K. Cheng and G.Q. Wang studied quality assurance framework of the European Association of Distance Teaching Universities, African Virtual University, Australian, USA and Asian Association of Open University, found that each quality dimension includes the key issues, management system, work tasks, procedures and methods to ensure the quality of distance education, which provides the best basis for distance education institutions to improve the quality of education [5].

In China, many teachers only regard distance education as a means of replacing classroom teaching with innovation, but they cannot really adapt to the distance teaching environment and achieve classroom teaching objectives through the way of distance classroom teaching. Some schools even take the setting of distance education courses as an evaluation index, but the actual teaching investment is seriously insufficient. They only do the most basic online work of course resources, and the actual investment in distance education courses needs to be further increased.

This paper intends to explore the distance education system based on dual-mode teaching, and to study the quality control of each teaching process in distance education.

\section{Design Of THE Distance EdUCATION SYSTEM With DUAL-MODE TEACHING}

The operation mode of distance education software is usually to teach the course content to learners through network media resources such as course teaching video, sound, picture and course teaching PPT, and to evaluate the learning effect through online examination.

\section{A. Teaching Mode of the Distance Education}

In general, there are two types of distance education, synchronous and asynchronous. Synchronous learning requires all students to participate the classes at the same time. 
The method of delivery is usually interactive and includes Internet chat sessions, teleconferences tele courses, and web conferencing, such as the VIPKID. Asynchronous instructions are more flexible because it didn't require simultaneous participation of all learners in the class [6].

Internet-based distance education has become a specific focus for at least three reasons according to the Institute for Higher Education Policy (IHEP) [7]. Currently, most of the resources for distance education are the teaching videos, such as MOOCs [8], SPOCs, etc. These are belonged to single mode distance education system.

\section{B. System Design for Distance Education with Dual-Mode Teaching}

The distance education system with double mode is mixing type of both synchronous and asynchronous (Fig. 1). The education resources during the instructional procedure are the teaching videos, voices or PPT slides, which belonged to the asynchronous mode. The resources during the review procedure are the knowledge about the important and difficult points delivered by the virtual teacher which belonged to the synchronous mode. The test procedure is belonged to the asynchronous mode and the Evaluation of classroom question and answering procedure belonged to the synchronous mode.

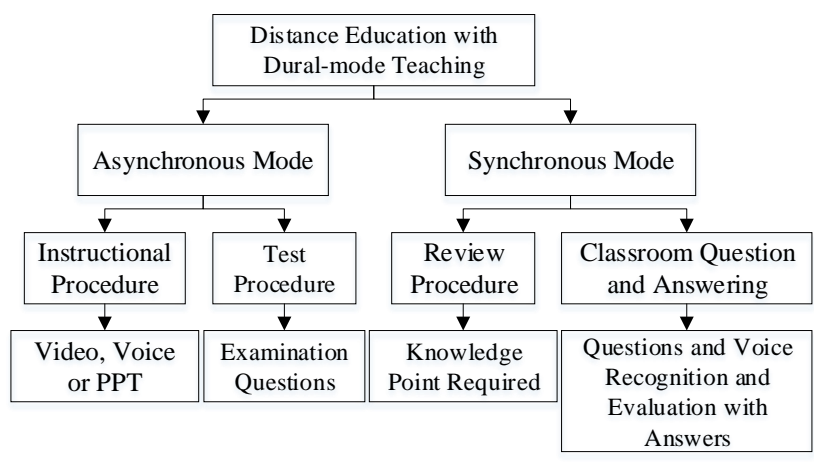

Fig. 1. Design of distance education system with dual-mode teaching.

The examination questions must be carefully prepared during the test procedure by the teachers and the automatic generation of examination system, which contains items management and automatic questionnaire generation must be integrated. Furthermore, the corresponding automatic marking system could also be developed for marking the examination in time.

The review procedure not only demands the learning management system to search the knowledge points among the resources and provide the search result to the student properly, but also the teacher is required to decompose the teaching content according to knowledge points and establish corresponding database for query and matching, which need the supports of the expert system, to conduct in-depth learning of knowledge points through teaching management system, and to use artificial intelligence to present knowledge points through virtual teachers in the teaching system. When the distance education system is developed with the Unity 3D and VR/AR, the effects of the teaching will be better.

Like the test procedure, the classroom question must also be carefully prepared and the answering voice or the text should be recognized for further comment [9].

\section{Human-Computer Interactive Interface}

Unity has become the leading platform for building virtual reality applications, and the experiences for this new generation of consumer VR devices. By using the Unity to develop VR applications that can be experienced with devices such as Oculus, Daydream, and Vive [10].

For the reasons above, the distance education system with double teaching mode are suggested to be developed by the Unity 3D.

\section{Software and the VR/AR Device}

Now the game has potential in distance education in the time of Internet plus. Currently, the internet games have great attraction for college students, some of the students are indulging in them and neglecting the study of professional courses. Therefore, the development of a suitable virtual distance education platform, combining games with professional education, has a good role in promoting students' professional courses learning.

The real time platform, powered by tools and services of the Unity is used to create half of the world's games and offer incredible possibilities for game developers, and creators across industries and applications. The Unity 3D has the powering over two-thirds of VR and AR experiences and the Unity is the preferred development tool for the majority of XR creators. Unity is the best and most valuable solution for jumping into the latest and greatest immersive technologies to the distance education with VR/AR.

AR/VR device provides an immersive way to show the content of teaching relying on games. Unlike gaming and entertainment, novelty and engagement aren't important learners. The AR/VR medium brings a lot of unique advantages and immersive applications can better utilize spatial memory, create a strong sense of presence, provide an additional dimension for displaying information, and take advantage of our natural ability to navigate 3D worlds, such as the virtual classroom.

\section{Process Control Measures of Teaching Quality ASSURANCE}

Distance education involves three factors, including distance education curriculum teachers, distance course students and distance education platform developers. As the normal distance education system, the teaching quality of the system with dual-mode teaching could be controlled from the follow measures.

\section{A. Measures from the Teachers}

For teachers, the first is the professional development of teachers. At present, there are imbalances in the development of teachers, including the region and the quality of training.

In order to guarantee the teaching quality, it is necessary for the teacher to attend the teacher professional development. Traditionally, the teachers were trained in the form of workshops only after being released from their obligations. And the teachers in developing countries face historical and systematic inequity in access to professional development [11].

The inequity in teacher professional development also 
manifests in quality. The traditional workshop typically focuses on delivering the information through expert presentations, which may raise teachers' awareness of certain topics but fail to catalyze changes of the real-world in their distance education practice [12].

Thus, an urgent need for innovative solutions to guarantee the equity, quality, and efficiency in teacher professional development is imperative. The making of distance courses should be based on teaching design, guided by teaching theory, learning theory and communication theory, pay attention to the design of content, strategy and evaluation of distance courses, and pay special attention to enhancing the interaction of courses, so that learners could learn separately from teachers and feel humanistic care.

There are following suggest for course teachers of the distance education to improve the teaching effect.

Firstly, the model of distance education lacks the corresponding evaluation system, the relevant teaching content and teaching process lack basic system norms, and there is no unified standard. Teachers in distance education courses have some coping behaviors in the preparation of teaching resources, the design of teaching links and the interaction with students, which leads to the development of distance education work with obvious randomness.

Secondly, in view of the isolation between teachers and students in distance education and the existing problems, corresponding measures should be carried out to minimize the adverse effects, so that students do not feel inappropriate and answer questions in a timely manner. It is suggested that a team should be set up to answer students' questions in distance courses. In addition, curriculum forums are set up to allow the teachers to regularly exchange knowledge about the curriculum. In order to develop interactive teaching quality, students should be consulted when carrying on the teaching designing, and their initiative in participating in distance education should be mobilized so as to enable students to participate in distance education on their own initiative. In the aspect of teaching design, the interactive teaching module should be strengthened through putting forward questions, analyzing problems, solving problems and other related links, so that students can apply the basic theoretical knowledge they have learned to practice, realize the overall improvement of students' comprehensive literacy, arrange relevant after-class exercises according to what they have learned, provide directional guidance for students' autonomous learning, and finish in groups. Make corresponding learning tasks, so as to strengthen the communication between students.

Thirdly, high-quality interpersonal interaction is an important factor affecting learners' learning effects [13]. To improve the quality of interpersonal interaction, teachers must have good information literacy so as to provide effective help to learners when they encounter difficulties.

Lastly, for different distance learners, curriculum resources and teaching design should be differentiated. This requires that the course teachers can understand the corresponding situation of learners well in advance, including students' preferences for teaching courses, preferred ways of communication, and so on.

\section{B. Requirements for Learners}

Learners in different groups may have different attitudes towards distance education, which will directly affect the choice of distance learning and the success of distance learning. Young learners in China, especially those who have just entered universities, may be more adapted to the traditional education model. After all, they are accustomed to teachers' teaching and guidance face-to-face in secondary schools. Distance learning is likely to make them feel lack of support and motivation, and eventually give up distance learning. In contrast, the older learners are more enthusiastic about distance learning because they do not have the conditions to receive the corresponding education and have strong learning motivation and self-learning ability.

The separation of teachers and learners in distance education leads to the decrease of control over learning activities of the learners. Distance education learners spend most of their time studying independently by using the media and cannot communicate face-to-face with teachers and other learners. Therefore, on the one hand, learners' preference to the courses will directly affect their learning effect. On the other hand, in order to maintain learners' attention and achieve normal teaching effect, teachers in distance education must use appropriate teaching methods to solve a series of problems caused by the separation of teachers and learners. This could be achieved by the teachers through curriculum design.

It is necessary for distance education learners to participate group discussions and interactive question-and-answer learning than to simply read through the media or listen to online teachers. In addition, the attitudes towards distance learning could be improved by strengthening the supervision and help to the learners. In addition, it is necessary for learners with low learning ability to carry out learning skills training to adapt to the requirements of distance education. The training includes two levels: technical information literacy and humanistic information literacy. Information literacy reflects people's knowledge and ability to use information, while humanistic information literacy reflects people's understanding of the value of information and their psychological state in the face of information. Emphasis is placed on training learners to make full use of information technology to obtain the required learning resources, including various resources presented in the form of traditional media, especially to train learners to make full use of the Internet for network retrieval, query and access to information.

On the other hand, distance education puts forward higher requirements for learners' learning ability. Effective training of learning strategies is an effective measure to improve the quality of distance education.

\section{Requirements for Developers of Distance Education Platform}

In the process of distance education, if there are problems in the hardware function or the software design of distance education platform, the learners will feel frustrated in learning.

Reasonably, the instructional design could increase the probability of interpersonal interaction, enhance the learning 
interest of distance education learners, and then enhance the teaching effect. Similarly, for distance education platform developers, the improvement of human-computer interaction interface and interaction quality can also significantly improve the teaching effect.

Human-computer interaction in distance education is actually the interaction between learners and teaching resources. In order to improve the learning interest and quality of learners, teaching software should strengthen the interactive design of learning content. Especially in the distance teaching of double teaching mode, we should pay attention to the design of man-machine interface and navigation. The design of interaction should consider the difference of the learners in learning styles and stimulate the motivation of the learners as much as possible. The core of all this is to establish the learner-centered thinking.

Furthermore, when develop the platform with Unity 3D and the VR/AR devices, the virtual classroom and the teacher combined with the expert system with the knowledge of the courses and the recognition of the input of the learners, such as the characters entered by keyboard or handwriting board, voice input through the microphone[14].

During the procedure of classroom question and answering, the vivid figure of the teacher should be designed properly and could respond to the learner in time.

The duty of the course teachers, learners and platform developers for the distance education is show as Fig. 2.

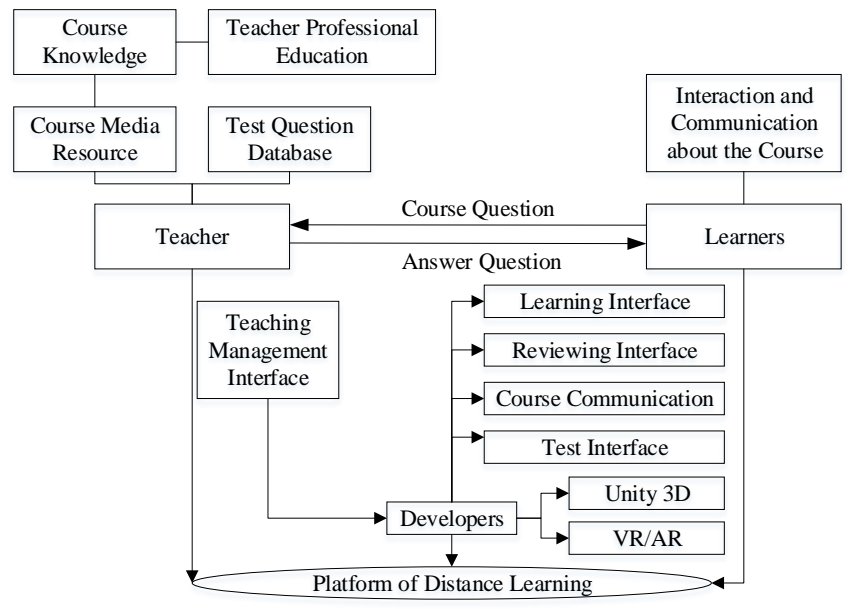

Fig. 2. Duty of the course teachers, learners and developers.

\section{INSTRUCTIONAL DESIGN}

The level of curriculum design is an important factor affecting the attitudes of learners towards distance courses. The quality of curriculum design has a direct impact on teaching effect. Better curriculum design can promote distance learning and enhance learning effect.

\section{A. Instructional Design}

In the design of dual-mode distance education platform, the teaching links are based on course preview, virtual course prediction, virtual classroom teaching, virtual classroom questioning, virtual classroom testing and online course examination. Course online exams include monthly exams, mid-term exams, final exams and follow-up review exams. The nature of the examination includes self-test and formal examination (Fig. 3).

For example, after the course preview, it needs a simple course prediction test to formally enter the virtual classroom teaching. In the process of virtual classroom teaching, virtual teachers may randomly ask questions in the classroom, and need to answer in order to carry out the follow-up teaching. The virtual classroom test of this course is carried out after classroom teaching. Course exams are given randomly by automatic question-setting system. Self-test questions are objective ones, and the results are given in real time. Formal exams include standardized ones for subjective and objective ones, and the results are logged in by teachers after marking the papers.

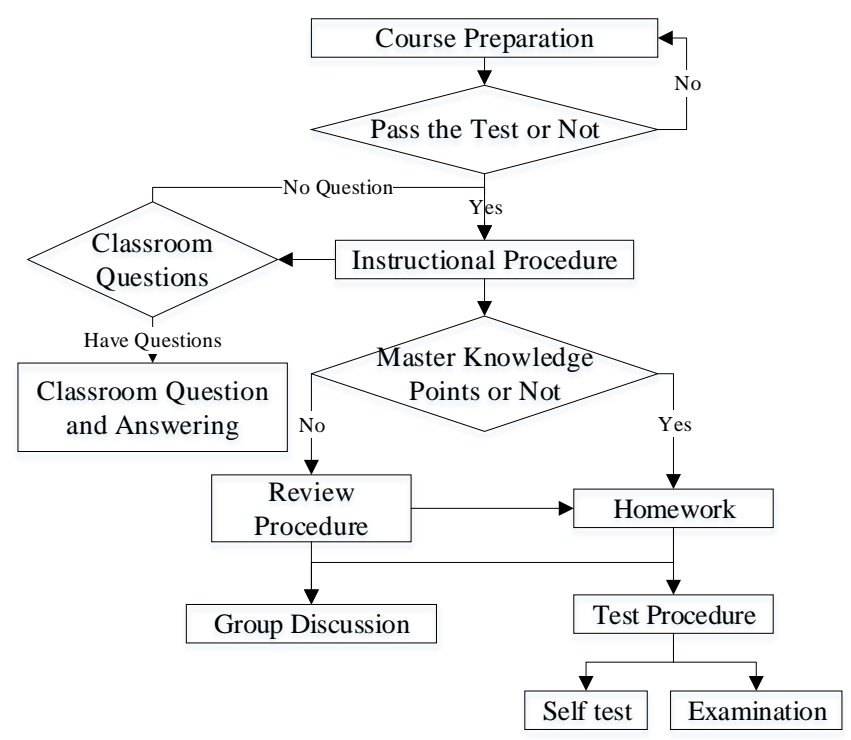

Fig. 3. Instructional design.

\section{B. Interpersonal Interaction in Instructional Design}

Teachers not only give timely encouragement, feedback and evaluation, but also establish solid links with learners through letters, telephone calls, email and so on. Before the beginning of the course, it is better to investigate the environmental factors around the learners so as to give the learners with learning difficulties the necessary encouragement and support to help them succeed in learning. In addition, although advanced technology provides convenient conditions for teachers and learners to communicate, it does not mean that teachers and learners will actively and frequently communicate and communicate, so it is necessary for distance teaching to put forward requirements for counseling and answering activities. For example, there are two ways for teachers to help learners in online teaching: answering questions online and tutoring after class. Teachers should have a fixed time to answer questions online. Teachers should sort out the unsolved questions online and send the answers to learners through teaching forums or e-mail in time.

\section{EFFECT ASSESSMENT OF DistANCE EDUCATION}

Theory of Learning suggests that learning takes place through our intrapersonal and interpersonal conversations and that formative assessment practices help to shape and regulate this dialogue in higher education courses. In the study, the 
seven principles of good assessment feedback [15] put forward by Nicol and Macfarlane-Dick are used developed. These assessment principles clearly align with the concept of an educational community of inquiry, and they are composed of assessment feedback from self, peer, instructor, external experts, learners and developers.

The self-assessment activities that utilize rubrics can be used to support this cognitive process in a distance learning environment. The peer-assessment activities can be finding a convenient place and time for all students to meet outside of the classroom. The instructor assessment practices in distance education are often limited to high-stakes summative assessment activities such as midterm and final examinations.

Besides, external experts could also provide assessment feedback on individual or group presentations through web-based video technologies. The developers will provide an assessment for the teaching effects of the distance learning course due to their experience in developing of distance education platform.

The assessment of learners could be gathered by online surveys or questionnaires.

The assessment from self, peer, instructor, experts, developers and learners should be an integrated process in a community of inquiry, rather than a series of isolated events, in order to help learners, develop their own cognitive skills and strategies.

\section{CONCLUSION}

This study offers a new system design of distance education with dual-mode teaching, which could be running under both synchronous and asynchronous mode. The instructional procedure and the test procedure belonged to the asynchronous mode. The review procedure and the classroom question and answering procedure belonged to the synchronous mode.

In order to guarantee the teaching effect of the distance education, the teachers must have good information literacy so as to provide effective help to learners when they encounter difficulties. And distance education puts forward higher requirements for learners' learning ability. Effective training of learning strategies is an effective measure to improve the quality of distance education. In order to provide a better learning experience, the developers of teaching platform should provide friendly interpersonal interaction and human-computer interaction interface. Besides, proper teaching stage design and interpersonal interaction during instructional design could also improving teaching effect.

\section{CONFLICT OF INTEREST}

The author declares no conflict of interest to this work.

\section{AUTHOR CONTRIBUTIONS}

Chunye Tuo had completed the study independently. She contributed to the literature research, wrote the paper and had approved the final version.

\section{REFERENCES}

[1] S. R. Markovic', N. Jovanovic', R. M. Popovic', and S. Cvetanovic', "Development UML model of distance learning system," in Proc. 7th International Conference on Telecommunications in Modern Satellite, Cable and Broadcasting Services, pp. 605-610, vol. 2, 2005.

[2] K. K. Mümine and Ö. Selma, A Review of Distance Learning and Learning Management Systems, 2016.

[3] A. Oyaid and A. Al-Hosan, "Towards identifying quality assurance standards in virtual learning environments for science education," Pertanika J. Soc. Sci. \&Hum. vol. 20, no. 3, pp. 798-28. 2012.

[4] P. V. J. Pitsoe and D. Mpho, "Cultural hegemony in open distance learning: Does it really matter?" Mediterranean Journal of Social Sciences, vol. 4. pp. 83-90, 2013.

[5] X. K. Cheng and G. Q. Wang. "International experience of distance education quality assurance: A comprehensive framework: Analysis and synthesis of five representational quality assurance frameworks," Adult Education, no. 2, 2019.

[6] M. E. Lease, "Different type of distance education," Computers in Libraries, vol. 19, no. 2, p. 35, 1999

[7] J. P. Merisotis and R. A. Phipps, "Quality on the line: Benchmarks for success in internet-based distance education," IHEP Report, National Education Association (NEA), 2000.

[8] G. Siemens, "Massive open online courses: Innovation in education?" Open Educational Resources: Innovation, Research and Practice, pp. 5-15, January 2013.

[9] A. A. Ambrose et al., "Developing e-examination voice interface for visually impaired students in open and distance learning context," presented at Conference on Information Communication Technology.

[10] J. Linowes, Unity Virtual Reality Projects, 2nd Edition, Packt Publishing, 2018.

[11] B. Robinson, "Using distance education and ICT to improve access, equity and the quality in rural teachers' professional development in Western China," International Review of Research in Open and Distance Learning, vol. 9, no. 1, pp. 1-17, 2008.

[12] G. Kleiman, M. A. Wolf, and D. Frye, "The digital learning transition MOOC for educators: Exploring a scalable approach to professional development," Friday Institute for Educational Innovation, College of Education, NC State University, Raleigh, US, 2013.

[13] V. D. B. Geesje, "How important is interaction to students? A case study in open distance learning. Source," in Proc. the International Conference on e-Learning, pp. 463-470, July 2018.

[14] W. L. Krug, "Analysis of mouse movement and body response in distance learning environments," Source: Communications in Computer and Information Science, vol. 735, pp. 595-607, 2017

[15] D. J. Nicol and D. Macfarlane-Dick, "Formative assessment and self-regulated learning: A model and seven principles of good feedback practice," Studies in Higher Education, vol. 31, no. 2, pp. 199-218, 2006.

Copyright (C) 2019 by the authors. This is an open access article distributed under the Creative Commons Attribution License which permits unrestricted use, distribution, and reproduction in any medium, provided the original work is properly cited (CC BY 4.0).

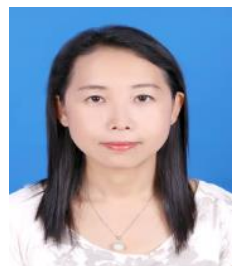

Chunye Tuo was born on April 11, 1982 in Yan'an city, graduated from Yan'an University with an undergraduate degree in history after receive 4-year undergraduate education in Yan'an city, China, and graduated from Party School of Shaanxi Provincial Party Committee with a master's degree in law after 3-year graduate education in Xi'an, China.

She works in Shaanxi Xueqian Normal University, and engaged in educational management and has taught educational psychology and related courses in pedagogy. 